INTIQAD: JURNAL AGAMA DAN PENDIDIKAN ISLAM

ISSN 1979-9950 (print) || ISSN 2598-0033 (online), http://jurnal.umsu.ac.id/index.php/intiqad DOI: $10.30596 /$ intiqad.v\%vi\%i.3265

Vol. 11, No. 2 (Desember 2019)

\title{
Implementasi Kurikulum Al-Islam dan Kemuhammadiyahan dalam Meningkatkan Sikap Religiusitas Mahasiswa di Universitas Muhammadiyah Sumatera Utara
}

\author{
Nur Rahmah Amini ${ }^{1 *}$, Nadlrah Naimi ${ }^{2}$, Said Ahmad Sarhan Lubis ${ }^{3}$ \\ Universitas Muhammadiyah Sumatera Utara ${ }^{* 1,2,3}$ \\ *1email: nurrahmah@umsu.ac.id \\ ${ }^{2}$ email: nadlrahfaiumsu@gmail.com \\ 3email: saidadmad@umsu.ac.id
}

\begin{abstract}
Muhammadiyah University of North Sumatra (UMSU) is the Best Private University in North Sumatra. From innovative and innovative education and learning programs, finally students can become competent, intelligent and trustworthy and have exceptional competitiveness at both National and International levels. In realizing maximum education, especially in the formation of student religiosity attitudes that are in accordance with the values of Al-Islam and Kemuhammadiyahan, the Muhammadiyah University of North Sumatra (UMSU) in collaboration with the Al-Islam Agency and kemuhammadiyahan (BIM) formed Al-Islam learning curriculum and Kemuhammadiyahan is in accordance with the guidance of the Muhammadiyah tarjih. As lecturers in Al-Islam and Kemuhammadiyahan courses, we must have targets in learning, for example various innovations that we need to implement in learning activities so that students can have a religious attitude and can understand the values of Al-Islam and Kemuhammadiyahan well and practice in everyday life. This study aims to find out the extent of the role of Al-Islam Kemuhammadiyahan subjects in developing the attitude of religiosity of students at Muhammadiyah University in North Sumatra. This study uses mixed method with analytical descriptive style with IPO approach (Inputs, Processes and Products), because there are differences in religious understanding from respondents in different situations
\end{abstract}

Keywords: Al-Islam Curriculum and

Kemuhammadiyahan, Religiosity and Students.

Abstrak

Universitas Muhammadiyah Sumatera Utara (UMSU)

merupakan Universitas Swasta Terbaik di Sumatera Utara.

Copyright (C 2019. Intiqad: Jurnal Agama dan Pendidikan Islam. This is an open acces article under the CC-BY-SA lisence (https://creativecommons.org/licenses/by-sa/4.0/). 
Dari program pendidikan dan pembelajaran inovasi dan inovatif akhirnya bisa menjadikan mahasiswa yang berkompeten, unggul cerdas dan terpercaya serta mempunyai daya saing yang sangat luar biasa baik tingkat Nasional dan International. Dalam mewujudkan pendidikan yang maksimal, terutama dalam pembentukan sikap religiusitas mahasiswa yang sesuai dengan nilai-nilai Al-Islam dan Kemuhammadiyahan, maka Universitas Muhammadiyah Sumatera Utara (UMSU) bekerjasama dengan Badan Al-Islam dan kemuhammadiyahan (BIM) membentuk kurikulum pembelajaran yang lebih berkualitas. Sebagai dosen mata kuliah Al-Islam dan Kemuhammadiyahan, kita harus mempunyai target dalam pembelajaran, misalnya berbagai inovasi yang perlu kita terapkan dalam kegiatan pembelajaran agar bisa mewujudkan mahasiswa yang mempunyai sikap religiusitas serta bisa memahami nilai-nilai Al-Islam dan Kemuhammadiyahan dengan baik serta diamalkan dalam kehidupan sehari-hari. Penelitian ini bertujuan untk mengetahui sejauh mana peran matakuliah Al-Islam Kemuhammadiyahan dalam membangun sikap religiusitas mahasiswa di Universitas Muhammadiyah Suamtera Utara.

Kata Kunci : Kurikulum Al-Islam dan Kemuhammadiyahan, Religius dan Mahasiswa.

\section{A. Pendahuluan}

Universitas Muhammadiyah

Sumatera Utara (UMSU) sangat berperan aktif dalam memajukan dunia pendidikan untuk mewujudkan generasi penerus bangsa yang beriman, bermoral, berilmu dan berpendidikan. Dalam membina mahasiswa agar mempunyai sikap religiusitas sangat dibutuhkan kerjasama yang baik dalam sistem kurkulum Al-Islam dan
Kemuhammadiyahan. ${ }^{1}$

$$
\text { Matakuliah Al-Islam dan }
$$

Kemuammadiyahan merupakan matakuliah wajib yang harus diprogram oleh mahasiswa Universitas Muhammadiyah Sumatera Utara yang dilaksanakan dalam 4 semester. Dengan harapan mata kuliah tersebut

${ }^{1}$ Syamsul Arifin, "Rekonstruksi Al-Islam Kemuhammadiyahan Perguruan Tinggi Muhammadiyah sebagai Praksis Pendidikan Nilai”, Jurnal Edukasi, Vol 13 No.2 (2015), h. 54 
INTIQAD: JURNAL AGAMA DAN PENDIDIKAN ISLAM

ISSN 1979-9950 (print) || ISSN 2598-0033 (online), http://jurnal.umsu.ac.id/index.php/intiqad DOI: 10.30596/intiqad.v\%vi\%i.3265

Vol. 11, No. 2 (Desember 2019)

memberikan pengetahuan dan pemahaman terhadap nilai-nilai Al-Islam dan Kemuhammadiyahan. Pengetahuan dan pemahaman yang baik diharapkan mampu di implementasikan oleh mahasiswa dalam kehidupan sehari-hari.

Namun realita yang terjadi saat ini, masih banyak mahasiswa yang belum mempunyai sikap religiusitas dalam dirinya. Mahasiswa yang tidak mempunyai etika yang baik pasti ia tidak mempunyai sopansantun dan akhirnya ia tidak bisa merubah dirinya lebih baik lagi. Kemudian kita juga melihat saat ini masih banyak mahasiswa yang belum aktif dalam menjalankan shalat wajib lima waktu sehingga dirinya mudah tejerumus kedalam hal-hal yang negative. $^{2}$

Untuk itu, sebagai pegajar dan guru yang baik haruslah bisa mendidik mahasiswa dengan diberikan ilmu yang bermanfaat kepada mereka sehingga visi dan misi di Universitas Muhammadiyah Sumatera Utara (UMSU) bisa terwujud dengan kualitas yang baik.

2 Puspita Handayani, "Pendidikan Karakter Matakuliah AIK1 terhadapPerilaku Mahasiswa Fakultas Ekonomi dan Bisnis Universitas Muhammadiyah Sidoarjo", Prossiding Seminar Nasional Pendidikan, (2016), h. 324
Salah satu untuk mencapai langkah yang baik dalam mewujudkan mahasiswa yang bersikap religiusitas dengan menggunakan penekanan metode keteladanan dalam pembelajaran AlIslam dan Kemuhammadiyahan. ${ }^{3}$

Melihat berbagai permasalahan yang ada terhadap mahasiwa maka kami mengambil judul penelitian implementasi kurikulum Al-Islam dan Kemuhammadiyahan dalam meningkatkan sikap religiusitas mahasiswa di Universitas Muhammadiyah Sumatera Utara (UMSU).

\section{Fokus Penelitian}

Adapun fokus masalah yang akan dikaji dalam penelitian ini adalah sebagai berikut:

1. Bagaimana sikap religiusitas tumbuh dalam diri mahasiswa pada mata kuliah Al-Islam dan Kemuhammadiyahan di UMSU?

2. Bagaimana peran mahasiswa dalam implementasi kurikulum Al-Islam dan Kemuhammadiyahan di kelas?

\section{Tujuan Penelitian}

Tujuan penelitian ini adalah membangun sikap religiusitas

\footnotetext{
${ }^{3}$ Ibid, h. 327
} 
INTIQAD: JURNAL AGAMA DAN PENDIDIKAN ISLAM

ISSN 1979-9950 (print) || ISSN 2598-0033 (online), http://jurnal.umsu.ac.id/index.php/intiqad DOI: $10.30596 /$ intiqad.v\%vi\%i.3265

Vol. 11, No. 2 (Desember 2019)

mahasiswa

di

Universitas

Muhammadiyah

Sumatera

Utara

(UMSU).

\section{Kajian Pustaka}

Penelitian terdahulu yang digunakan acuan peneliti saat ini diantaranya:

Pertama: Penelitian yang di tulis oleh Syamsul Arifin, Universitas Muhammadiyah Malang, Jurnal: 2015 dengan judul "Rekonstruksi Al Islam Kemuhammadiyahan Perguruan Tinggi muhammadiyah sebagai Praksis pendidikan Nilai". 4

Penelitian ini memaparkan bagaimana matakuliah Al-Islam dan Kemuhammadiyahan bisa terlaksanakan dengan baik sehingga mahasiswa UMSU mempunyai peran yang baik dalam meningkatkan sikap religiusitas. Dapat kita pahami bersama, bahwa pada kurikulum Al-Islam dan Kemuhammadiyahan terdiri dari mata kuliah agama, ibadah, muamalah dan kemuhammadiyahan.

Kedua, penelitian yang ditulis oleh Dr. Akif Khilmiyah, M.Ag dan Drs. Syamsudin, M.Pd. Laporan hasil

$$
\text { h. } 54 \text {. }
$$

penelitian hibah unggul PTM Universitas Muhammadiyah Yogyakarta."EvaluasiPembelajaran AIK dengan Pendekatan Social Emosional Learning (SEL) dalam Membentuk Karakter dan Akhlak Mulia". ${ }^{5}$

Penelitian ini bertujuan: untuk melihat kondisi bagaimana pembelajaran AIK di UMY, untuk mengukur kecerdasan emosional dan social mahasiswa dalam pembelajaran AIK, untuk melihat sejauh mana karakter mahasiswa dan akhlak dalam dirinya, serta membuat rencana pembelajaran kedepannya yang lebih baik lagi dalam meningkatkan kecerdasan emosional dan social mahasiswa dengan menggunakan pendekatan SEL (Social and Emotional Learning).

\section{B. Metode Penelitian}

Jenis penelitian ini adalah penelitian evaluatif ekspos facto. ${ }^{6}$ Dapat di jelaskan bawwa penelitian ini menggunaakan pendekatan Input, Proses, dan Produk). Lokasi penelitian

5 Akif Khilmiyah dan Syamsudin, Evaluasi Pembelajaran AIK dengan Pendekatan Social Emosional Learning (SEL) dalam Membentuk Karakter dan Akhlak Mulia. Laporan hasil Penelitian Unggul PTM. (2016).

6 Hasrian Rudi Setiawan dan Dani Abrianto, Metode Penelitian Kualitatif, (Yogyakarta: Bildung, 2019), h. 67. 
INTIQAD: JURNAL AGAMA DAN PENDIDIKAN ISLAM

ISSN 1979-9950 (print) || ISSN 2598-0033 (online), http://jurnal.umsu.ac.id/index.php/intiqad DOI: $10.30596 /$ intiqad.v\%vi\%i.3265

Vol. 11, No. 2 (Desember 2019)

ini dilaksanakan di Universitas

C. Pembahasan

Muhammadiyah Sumatera Utara

(UMSU) pada fakultas yang mengajarkann mata kuliah agama.

Teknik sampling yang digunakan dalam penelitian ini adalah purposive random sampling.

Subyek dalam penelitian ini terdiri dari 20 dosen Al-Islam dan Kemuhammadiyahan, serta mahasiswa yang masuk kelas di Fakultas Agama Islam, Ekonomi dan Bisnis, Hukum, Fisip, Teknik, Pertanian, Kedokteran, Keguruan dan Ilmu Pendidikan. Subjek penelitian ini dilakukan setelah tim peneliti mendapatkan hasil implementasi kurikulim Al-Islam dan Kemuhammadiyahn, lalu permasalahan tersebut dipecahkan dengan menggunakan berbagai metode pembelajaran dan hasilnya pembelajaran tersebut disosialisasikan kepada seluruh dosen AIK, kemudian seluruh dosen AIK harus menerapkan metode pembelajaran tersebut dengan tuuan agar bisa membentuk sikap religiusitas mahasiswa di Universitas Muhammadiyah Sumatera Utara (UMSU).

\section{Matakuliah Al-Islam dan} Kemuhammadiyahan

Dalam mewujudkan sikap religiusitas mahasiswa sangat penting untuk meningkatkan kualitas pembelajaran pada kurikulum Al-Islam dan Kemuhammadiyahan. Kulaitas pembelajaran matakuliah AIK adalah pondasi dalam diri mahasiswa dalam meningkatkan sikap religiusitas. Kita melihat realita yang terjadi saat ini masih banyak mahasiswa yang ketika pembelajaran berlangsung namun masih banyak yang tidak serius bahkan mahasiswa tersebut tidak serius dalam kegiatan pembelajara, hal inilah yang menjadikan mahasiswa tidak mempunyai karakter yang baik dalam dirinya.

Seiring perkembangan zaman yang semakin modern, kita harus mempunyai nilai tanggungjawa dalam mendidik mahasiswa sehingga mereka tidak terjerumus kedalam perbuatan yang negatif dan mereka bisa menjadi mahasiswa yang cerdas, berpendidikan dan mempunyai moral serta akhlak yang mulia.

Inilah pendidikan Islam yang berkemajuan. IPTEKS adalah hasil pemikiran rasional secara holistik dan 
INTIQAD: JURNAL AGAMA DAN PENDIDIKAN ISLAM

ISSN 1979-9950 (print) || ISSN 2598-0033 (online), http://jurnal.umsu.ac.id/index.php/intiqad DOI: $10.30596 /$ intiqad.v\%vi\%i.3265

Vol. 11, No. 2 (Desember 2019)

komprehensif atas realitas alam semesta (ayat kauniyah) dan atas wahyu dan sunnah (ayat qauliyah) yang merupakan satu kesatuan.

a. Maka Al-Islam dan

Kemuhammadiyahan

(AIK)

Merupakan Matakuliah wajib bagi semua Universitas Muhammadiyah se-Indonesia, termasuk Universitas Muhammadiyah Sumatera Utara (UMSU) yang ditempuh empat semester 1. mata kuliah akidah dan akhlak, semester 2 mata kuliah ibadah, semester 3 mata kuliah muamalah dan semester 4 mata kuliah kemuhammadiyahan. Dengan mata kuliah Al-Islam dan Kemuhammadiyahan, ditargetkan bisa mewujudkan sikap religiusitas mahasiswa di Universitas Muhammadiyah Sumatera Utara (UMSU).

b. Religiusitas Manusia dalam Prespektif Islam Konsep religiusitas dalam Alquran berperan pada akidah dan tauhid. Artinya bahwa akidah dan tauhid mempunyai nilai yang baik dalam menjalani kehidupan sehari-hari. Sebagai seorang muslim yang beriman kepada Allah, akidah dan tauhid merupakan pondasi kekuatan dalam iman, sehingga iman yang kuat dan baik pasti akan berada dijalan yang benar, tetapi sebaliknya jika akidah dan tauhid lemah, pasti manusia mudah terjerumus kedalam hal yang negatif. Hal inilah yang harus menjadi butiran renungan hidup, bahwa pada hakikatnya religiusita manusia terlihat dari amalan sehariharinya, jika amalannya baik, pasti imannya akan terjaga. Dengan demikian, sebagai manusia biasa, haruslah mempunyai niat yang mulia dan mampu menjadikan diri ini untuk dekat kepada Tuhan yang Maha Esa, dengan perbuatan yang baik pasti akan membawa diri ini untuk meraih derajat taqwa disisiNya.

Religiusitas identik dengan istilah Akhlak dalam Islam sehingga, karakter mahasiswa kali ini yang menjadi fokus peneliti merupakan akhlak dari mahasiswa. Grand desain penelitian ini merupakan upaya pembiasaan atau proses pembudayaan nilai-nilai luhur di tingkat pendidikan Tinggi dalam Islam penanaman nilai-nilai luhur dalam berpikir, bersikap, dan berperilaku baik sehingga terwujudnya mahasiswa yang 
Vol. 11, No. 2 (Desember 2019)

bersikap religiusitas serta taat kepada Allah.

Sebagaimana firman Allah QS AdDahriyat: 56 yang artinya: "Dan aku tidakmenciptakan jin dan manusia melainkan supaya mereka mengabdi pada-KU”. Kemudian Allah berfirman dalam QS. al-Bayyinah: 5, yang artinya:" padahal mereka tidak disuruh kecualisupaya menyembah Allah dengan memurnikan ketaatan kepadaNya dalam (perjalanan) agama yang lurus, dan supaya mereka mendirikan shalat dan menunaikan zakat, dan yang demikian itulah agama yang lurus."

Maka dari beberapa penjelasan di atas pendidikan religiusitas Islami bisa dilakukan oleh orang yang bertaqwa sehingga mampu menunjukkan dia sebagai hamba dan khalifah Allah. Pendidikan karakter Islam adalah menjadikan anak didik sebagai hamba Allah dan Khalifah Allah yang berkualitas yakni taqwa. kata taqwa meliputi semua aspek bidang mulai dari keyakinan hidup, ibadah (menghubungkan hamba dengan Tuhan), moralitas, interaksi sosial, cara berfikir, sampai dengan gaya hidup. Indikator indikator orang yang dalam Al-Qur'an dijelaskan: 1) memiliki keyakinan
(QS.2:3), 2) memiliki orientasi jangka panjang (QS.59: 18), 3) memiliki citacita yang tinggi (QS.2: 218), 4) memiliki speed dalam prestasi (QS.3:153,QS.5:48), 5) memanfaatkan waktu dengan efektif (QS. 23:1-3)

\section{Membangun}

Religiusitas

\section{Mahasiswa}

Manusia pada dasarnya memiliki dua sifat yakni fujur (cenderung pada keburukan) dan sifat taqwa (cenderung pada kebaikan). (QS.91:7-8) yang artinya: "Dan jiwa serta penyempurnaannya (ciptaannya). Maka Allahmengilhamkan kepada jiwa itu jalan kefasikan dan ketaqwaannya." dua dasar inilah yang menjadi dasar pembentukan karakter seseorang. Karakteristik manusia merupakan hasil tarik menarik antara nilai baik dan buruk, dalam bentuk energi positif dan energi negatif.

Energi positif merupakan nilainilai etis religius yang bersumber dari Tuhan, sedangkan energi negatif merupakan a-moral yang bersumber dari setan. Energi positif merupakan kekuatan spiritual berupan iman, islam dan ihsan yang berfungsi membimbing manusia menuju ketaqwaan. energipositif selanjutnya yakni 'aqluas- 
Vol. 11, No. 2 (Desember 2019)

salim (akal sehat), qalbun Salim (hati yang sehat), qalbun munib (hati yang suci dari dosa), dan nafsu mutmainnah (jiwa yang tenang). Energi positif mengandung sikap dan perilaku etis ini merupakan implementasi dari kekuatan spiritual dan kekuatan kepribadian manusiayang melahirkan nilai-nilai luhur.

Maka untuk mewujudkan insan yang berkarakter khususnya mahasiswa perlu adanya pembiasaan-pembiasaan dan juga pendukung untuk mewujudkannya. peneliti melihat bahwa kapasitas matakuliah Al-Islam dan Kemuhammadiyahan sebagi matakuliah penciri Perguruan Tinggi Muhammadiyah yang memiliki satuan kredit semester yang cukup banyak, dimungkinkan bisa menjadi sarana pembangunan akhlak mahasiswa melalui teori-teori riligiusitas, kemudian adanya kontrol perilaku dari semua aspek baik dosen dan pimpinan, dimungkinkan religiusitas tersebut akan terbangun meskipun butuh waktu yang lama.

\section{Temuan Penelitian}

1). Kegiatan survey awal dan persiapan pelaksanaan penelitian.

Dalam pelaksanaan kegiatan penelitian ini dilakukan dengan tiga kali tahapan, tahapan pertama yaitu mendata jumlah dosen al-Islam dan Kemuhammadiyahan dalam mata kuliah ibadah dan kemuhammadiyahan. Adapun data yang kami teliti yaitu dosen al-Islam dan Kemuhammadiyahan sebanyak 15 dosen.

Tahapan kedua, tim peneliti langsung melihat proses kegiatan belajar mengajar dikelas mulai hari senin tanggal 8 April 2019 sampai dengan hari senin tanggal 29 april 2019 sehingga bisa melihat bagaimana metode yang diajarkan oleh setiap dosen Al-Islam dan Kemuhammadiyahan dengan harapan bisa menjadikan mahasiswa mempunyai sikap religiusitas dalam dirinya.

2). Hasil Pelaksanaan Diskusi tentang Ilmplementasi Kurikulum Al-Islam dan Kemuhammadiyah dalam Meningkatkan Sikap Religiusitas.

Pelaksanaan diskusi ini dilaksasanakan pada hari Rabu tanggal 26 Juni 2019 di gedung $\mathrm{F}$ ruang 302 Universitas Muhammadiyah Sumatera Utara. Penelitian ini akan membahas beberapa agenda yang sangat penting dalam memberikan nilai kotribusi yang bermanfaat dalam menjadikan mahasiswa untuk mempunyai nilai religiusitas. 
INTIQAD: JURNAL AGAMA DAN PENDIDIKAN ISLAM

ISSN 1979-9950 (print) || ISSN 2598-0033 (online), http://jurnal.umsu.ac.id/index.php/intiqad DOI: $10.30596 /$ intiqad.v\%vi\%i.3265

Vol. 11, No. 2 (Desember 2019)

Materi pertama yang akan Muhammadiyah yang lebih istiqomah disampaikan oleh Ibu Nur Rahmah Amini, M.Ag yaitu tentang ilmplementasi kurikulum Al-Islam dan kemuhammadiyahan. Dapat kita jelaskan bahwa setiap perguruan tinggi haruslah mempunyai visi dan misi yang baik dalam mewujudkan mahasiswa yang berpendidikan, berilmu, bermoral dan beretika yang baik.

Salah satu perguruan tinggi swasta yang berkomperten dalam membangun dunia pendidikan adalah perguruan tinggi Muhammadiyah. Ingatlah perguruan tinggi Muhammadiyah mempunyai peran yang aktif, inovasi dan kreatif dalam mencerdaskan generasi penerus bangsa.

Maka salahsatu penelitia ini adalah bagaimana implementasi kurikulum AIK bisa dijalankan dengan benar sehingga mahasiswa yang di didik bisa berperan aktif dalam mewujudkan kader Muhammadiyah yang lebih maju dan produktif.

Kemajuan pendidikan ini juga berpengaruh bagi para kader Muhammadiyah yang mempunyai nilai religiusitas dalam dirinya, dengan demikian kita berharap dengan penelitian ini bisa melahirkan kader

sebagai generasi penerus bangsa.

Materi kedua tentang sikap religiusitas Mahasiswa yang disampaikan oleh Bapak Said Ahmad Sarhan Lubis, S.HI., M.HI. Religiusitas merupakan sikap yang mulia dan sangat berpengaruh dalam pembinaan akhlak mahasiswa. Materi ketiga akan di sampaikan oleh Ibu Nadlrah Naimi, MA tentang metode pembelajaran yang efektif dalam mewujudkan mahasiswa yang religiusitas. Penelitian diatas mendapatkan beberapa kesimpulan yang bermanfaat dan setelah itu seluruh dosen Al-Islam dan Kemuhammadiyahan akan mempunyai beberapa teori atau ilmu dalam melakukan pembelajaran Al-Islam dan Kemuhammadiyahan lebih efektif.

Adapun hasil penelitian oleh tim peneliti dikelas adalah sebagai berikut ini:

Motode pembelajaran yang dilakukan di fakultas FISIP yaitu dengan metode diskusi dan tanya jawab. Metode diskusi dan tanya jawab menjadi bagian hal yang terpenting dalam menyampaikan materi

Kemuhammadiyahan. Deskripsi peran dosen saat pembelajaran mempunyai keseriusan yang sangat baik sehingga 
Vol. 11, No. 2 (Desember 2019)

mahasiswa bisa menerima materi Kemuhamadiyahan. Adapun peran mahasiswa saat pembelajaran, mahasiswa serius dan aktif dalam bertanya sehingga menjadikan situasi pembelajaran dengan baik dan bisa dipahami.

Metode pembelajaran yang digunakan di fakultas Teknik Mesin pada mata kuliah Kemuhammadiyahan. Dapat dijelaskan bahwa metode kooperatif merupakan metode pembelajaran kelompok yang lebih dari dua orang, di mana setiap anggota kelompok harus saling membantu dan bekerja sama agar tugas kelompok yang dikerjakan bisa berjalan dengan baik dan hasil yang bagus.

Deskripsi peran dosen dalam penyampaian materi ini yaitu menyampaikan materi dengan bahasa yang santun serta diskusi yang berkesan menyenangkan. Selanjutnya, peran mahasiswa saat pembelajaran yaitu masih ada beberapa mahasiswa yang aktif bermain hp, ada juga mahasiswa yang rajin mendengarkan materi dan ada juga mahasiswa yang tidur saat jam belajar.

Metode pembelajaran yang dilakukan di fakultas Agama Islam dengan metode ceramah dan diskusi. Metode tersebut di lakukan dengan berbagai variasi agar mahasiswa lebih mudah memahami materi Kemuhammadiyahan yang disampaikan oleh dosennya. Peran dosen saat jam belajar berlangsung, ia menyampaikan materi kemuhammadiyahan dengan bahasa yang mudah dipahami oleh mahasiswa. Peran mahasiswa masih aktif dalam kegiatan diskusi dan saling bertanya sehingga lebih mudah untuk memahami materi kemuhammadiyahan. Metode pembelajaran yang dilakukan di fakultas Fisip yaitu menggunakan metode ceramah, diskusi, dan Tanya jawab. Metode ceramah ini merupakan metode yang biasa dikerjakan oleh setiap dosen dalam pembelajaran berlangsung, dengan metode ini diharapkan mahasiswa bisa memahami materi yang disampaikan oleh dosen.

Kemudian metode tanya jawab, diskusi, dan dialog biasanya dilakukan oleh mahasiswa agar bisa mendalami setiap materi yang dibahas dalam kegiatan pembelajaran. Deskripsi peran dosen dalam pembelajaran tidak hanya sebagai fasilitator saja, namun harus memberikan peran yang aktif dalam membimbing dan 
Vol. 11, No. 2 (Desember 2019)

memberikan pembelajaran dalam mata kuliah yang disampaikan.

Deskripsi peran mahasiswa saat pembelajaran, ada mahasiswa belajar secara mandiri dan kelompok. Ada juga mahasiswa yang ribut dan tidak aktif dalam pembelajaran yang berlangsung. Sebagai dosen yang aktif haruslah bisa memberikan metode pembelajaran yang baik kepada mahasiswanya agar bisa memahami materi yang diajarkan dengan baik.

Metode pembelajaran yang dilakukan di fakultas Pertanian yaitu dengan metode ceramah dan diskusi. Metode ini menjadi hal yang paling utama dalam kegiatan pembelajaran, dimana mahasiswa harus aktif dalam diskusi sehingga ilmu yang mereka dapat semakin bertambah dan bisa diaplikasikan dalam kehidupan seharihari.

Deskripsi peran dosen saat pembelajaran berlangsung yaitu dosen menyampaikan materi dengan buku panduan, setelah itu membuka waktu untuk tanya jawab. Peran mahasiswa saat pembelajaran berlangsung yaitu mahasiswa menyampaikan tugas persentasi sesuai materi yang dibagikan oleh dosennya.
Saat jam belajar berlangsung masih banyak mahasiwa yang dating terlambat, tidak membawa buku, sebagian bermain hp, cepat bosen dan cepat ingin keluar.

Metode pembelajaran yang dilakukan di fakultas Ekonomi Bisnis yaitu dengan metode ceramah, diskusi, praktek ibadah, penugasan jurnal dan miniriset serta pengajian disetiap ranting dan cabang Masjid Taqwa Muhammadiyah.

Deskripsi peran dosen dalam pembelajaran mata kuliah ibadah saat pembelajaran adalah dosen sebagai pengajar, artinya mentranfer ilmu kepada mahasiswa sehingga mahasiswa menjadi pintar dan mempunyai wawasan yang luas. Dosen sebagai pendidik, dalam mentranfer ilmu pengetahuan kepada mahasiswa dosen harus mampu melahirkan mahasiswa yang berilmu dan mempunyai akhlak yang baik.

Deskripsi peran mahasiswa saat pembelajaran, pertama saat didalam kelas mahasiswa harus turut serta dalam setiap pembelajaran yang diberikan dosen sehingga dapat memperoleh ilmu pengetahuan dan menambah wawasan. Kemudian saat diluar kelas mahasiswa dapat berperan mengikuti kegiatan- 
INTIQAD: JURNAL AGAMA DAN PENDIDIKAN ISLAM

ISSN 1979-9950 (print) || ISSN 2598-0033 (online), http://jurnal.umsu.ac.id/index.php/intiqad DOI: $10.30596 /$ intiqad.v\%vi\%i.3265

Vol. 11, No. 2 (Desember 2019)

kegiatan luar kampus untuk pengalaman organisasi.

Metode pembelajaran yang digunakan di fakultas Hukum berpariasi (Ceramah, Diskusi, Problem Solving, Cooverarttive Script). Deskripsi peran dosen saat pembelajaran dalam proses perkuliahan dosen berperan sebagai motivator, pendidik, pengajar, dan pembimbing.

Deskripsi peran mahasiswa saat pembelajaran mahasiswa harus saling menghargai dosen dan teman kelompok yang menjelaskan materi kuliah. Peran inilah yang harus dilakukan dalam setiap pembelajaran agar bisa menciptakan suasana pembelajaran yang kondusif.

Pembelajaran yang kondusif juga bisa mewujudkan mahasiswa yang cerdas, serta mempunyai perilaku yang baik dalam mewujudkan generasi penerus bangsa yang bermanfaat untuk agama serta masyarakat sekitar

\section{Simpulan}

Dari hasil kajian dan analisis serta pembahasan yang telah dilakukan dalam penelitian ini, maka dapat dijelaskan bahwa metode pembelajaran yang digunakan metode ceramah, kelompok, revieu materi. Deskripsi peran dosen. Membuka perkulian dengan salam, meminta mahasiwa membaca doa, mengambil absen, sembari melihat pakaian yang islami, memulai dengan membaca alquran, revieu materi minggu lalu, mengantarkan materi yang baru, diskusi kelompok, dan menyampaikan pada seluruh mahasiwa nendengarkan, bertanya dan mencatat seluruh pertanyaan serta mencatat jawabanya. Memberikan pedalaman materi diskusi, Memberikan tugas dikirim melalui email.

Peran mahasiswa menjawab salam, membaca doa, mendengarkan absen, berpakaian rapi, mengulang materi minggu lalu, diskusi kelompok, mencatat setiap pertanyaan serta jawabanya. Membuat tugas dirumah. Alat yang dugunakan buku ajar, infokus, lactop, spidol, kertas, pulpen.

Beberapa dokumen tim peneliti dalam melakukan penelitian terapan sebagai berikut ini: 
INTIQAD: JURNAL AGAMA DAN PENDIDIKAN ISLAM

ISSN 1979-9950 (print) || ISSN 2598-0033 (online), http://jurnal.umsu.ac.id/index.php/intiqad DOI: $10.30596 /$ intiqad.v\%vi\%i.3265

Vol. 11, No. 2 (Desember 2019)

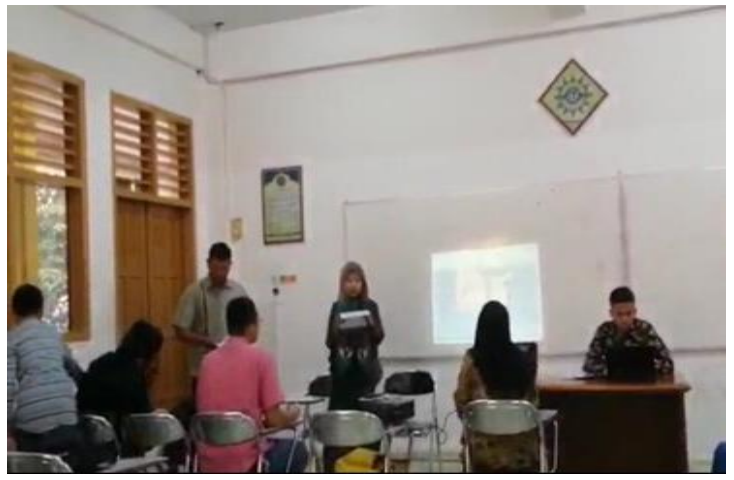

Gambar 1: Dosen Al-Islam dan Kemuhammadiyahan sedang memberikan pembelajaran dalam mata kuliah ibadah di Fakultas Fisip.

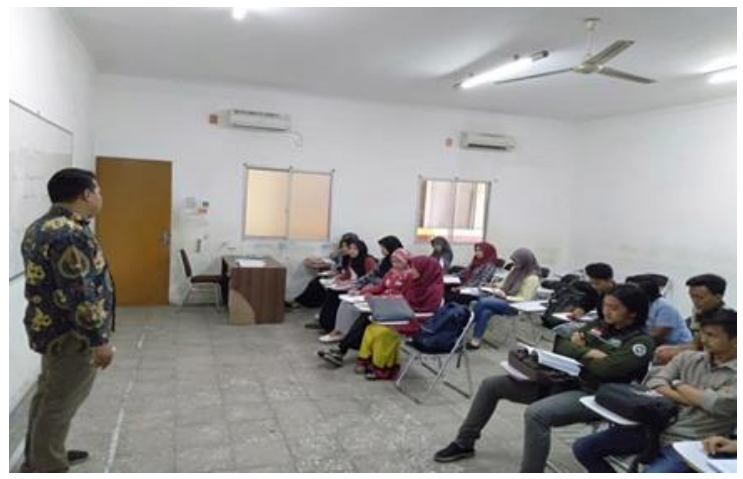

Gambar 2: Dosen Al-Islam dan Kemuhammadiyahan sedang memberikan pembelajaran dalam mata kuliah ibadah di Fakultas Ekonomi

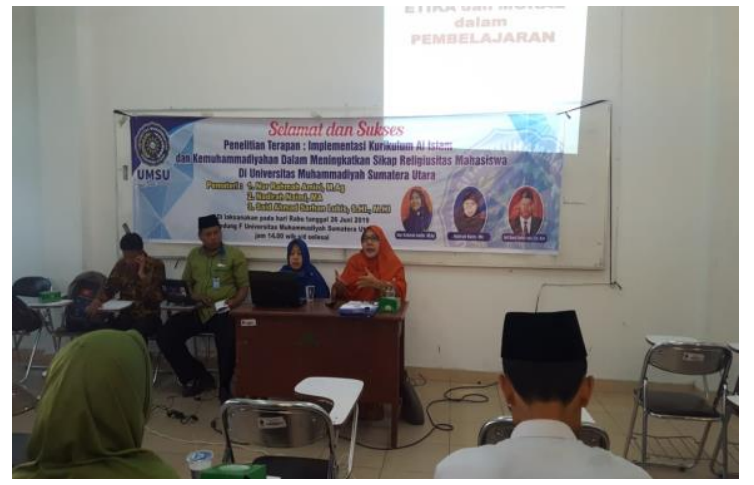

Gambar 3: Pelaksanaan penelitian bersama Dosen Al-Islam dan
Kemuhammadiyahan UMSU, Materi Kurikulum Al-Islam danKemuhammadiyahan yang disampaikan oleh ketua peneliti, Ibu Nur Rahmah Amini, M.Ag.

\section{Daftar Pustaka}

Arifin, Syamsul. (2015).

"Rekonstruksi

Al-Islam

Kemuhammadiyahan

Perguruan

Tinggi

Muhammadiyah sebagai

Praksis Pendidikan Nilai”.

Jurnal Edukasi Vol. 13 No. 2.

Handayani, Puspita. (2016).

Pendidikan

Karakter

Matakuliah AIK1 terhadap

Perilaku Mahasiswa Fakultas

Ekonomi dan Bisnis

Universitas Muhammadiyah.

Sidoarjo. Prossiding Seminar

Nasional Pendidikan.

Setiawan, Hasrian Rudi. Abrianto,

Dani. (2019). Metode

Penelitian Kualitatif.

Yogyakarta: Bildung.

Khilmiyah, Akif dan Syamsudin. (2016).

Evaluasi Pembelajaran AIK

dengan Pendekatan Social

Emosional Learning (SEL) dalam

Membentuk Karakter dan Akhlak 
INTIQAD: JURNAL AGAMA DAN PENDIDIKAN ISLAM

ISSN 1979-9950 (print) || ISSN 2598-0033 (online), http://jurnal.umsu.ac.id/index.php/intiqad DOI: $10.30596 /$ intiqad.v\%vi\%i.3265

Vol. 11, No. 2 (Desember 2019)

Mulia. Laporan hasil Penelitian

Unggul PTM.

Kopertais Wilayah IV Surabaya.

(2014). Pendidikan Karakter

Menjadi Berkarakter Muslim

Muslimah Indonesia.

Surabaya: Kopertis IV Press.

Said, Mohammad. (2011).

Pendidikan Karakter di Sekolah.

Surabaya: Jaringpena.

Sugiono. (2017). Metode Penelitian

Pendidikan pendekatan

Kuantitatif, Kualitatif, dan $R \& D$.

Bandung: Alfabeta. 